\title{
Developmental competence of prepubertal goat oocytes selected with brilliant cresyl blue and matured with cysteamine supplementation
}

\author{
Elisabeth RODRÍGUEZ-GONZÁLEZ $Z^{\mathrm{a}}$, Manel LÓPEZ-BEJAR ${ }^{\mathrm{b}}$, \\ Dolors IZQUIERDO ${ }^{\mathrm{a}}$, María-Teresa PARAMIO ${ }^{\text {a* }}$ \\ ${ }^{a}$ Departament de Ciència Animal i dels Aliments, Facultat de Vetèrinaria, \\ Universitat Autònoma de Barcelona, 08193 Bellaterra, Barcelona, Spain \\ ${ }^{\mathrm{b}}$ Departament de Sanitat i Anatomia Animals, Facultat de Vetèrinaria, \\ Universitat Autònoma de Barcelona, 08193 Bellaterra, Barcelona, Spain
}

(Received 2 January 2003; accepted 5 March 2003)

\begin{abstract}
The aim of this study was to assess the effect of oocyte selection using the brilliant cresyl blue (BCB) test plus the addition of cysteamine to the in vitro maturation (IVM) medium to improve the in vitro embryo development of prepubertal goat oocytes. The oocytes were exposed to $26 \mu \mathrm{M} \mathrm{BCB}$ and classified according to their cytoplasm coloration: $\mathrm{BCB}+$ (oocytes with blue cytoplasm) and $\mathrm{BCB}-$ (unstained oocytes). The oocytes were matured in a conventional IVM medium supplemented with cysteamine $100 \mu \mathrm{M}$. The control group consisted of oocytes not exposed to BCB and matured without cysteamine. The IVM-oocytes were inseminated and cultured in synthetic oviductal fluid (SOF) for 7 days. The normal fertilisation rate (oocytes showing 2 pronuclei and 1 sperm tail) of $\mathrm{BCB}+$ oocytes $(40 \%)$ was higher than those of $\mathrm{BCB}-(21 \%)$ and control oocytes $(22 \%)$. The percentage of morulae plus blastocysts was higher $(P<0.05)$ in the $\mathrm{BCB}+$ group than in the $\mathrm{BCB}$ - group (23.8 vs. 5.1\%, respectively). In conclusion, the integration of the $\mathrm{BCB}$ test and the addition of cysteamine in the protocol of in vitro embryo production from prepubertal goat oocytes has improved the developmental rates of embryo development.
\end{abstract}

embryo / IVF / IVM / thiol

\section{INTRODUCTION}

Brilliant Cresyl Blue (BCB) staining allows to determine the activity of glucose-6- phosphate dehydrogenase (G6PD) an enzyme synthesised in growing oocytes but with a decreased activity in oocytes that have finished their growth phase. Thus,

\footnotetext{
* Correspondence and reprints

E-mail: teresa.paramio@uab.es
} 
oocytes that have finished their growth phase show a decreased G6PD activity and exhibit a cytoplasm with a blue coloration because they do not reduce BCB to a colourless compound. The BCB test has been used successfully to select oocytes for IVM-IVF in pigs [1,2] and cows [3]. In our earlier study with prepubertal goat oocytes matured without cysteamine [4], we showed that oocytes exposed and stained with BCB are larger (136.6 vs. $125.5 \mu \mathrm{m}$ in diameter) and more able to develop to morula and blastocysts than unstained oocytes (12.0 vs. 3.6\%). However, blastocyst development rates were still lower $(4 \%$ in $\mathrm{BCB}+$ oocytes) than those obtained with oocytes from adult goats [5-9]. Prepubertal goat IVM-IVF-oocytes show a low incidence of male pronuclear (MPN) formation [10] and a high percentage of haploid embryos (59\% of $2-4$ cell embryos; [11]). The transformation of the fertilising sperm head into the MPN has been shown to be positively related to intracellular glutathione levels (GSH; [12]). De Matos et al. [13, 14], have shown that the addition of cysteamine to the maturation medium increases the GSH concentration in cow oocytes and improves the in vitro blastocyst yield. Moreover, the addition of cysteamine in the maturation medium increases the percentage of oocytes with decondensed sperm heads after IVF in pigs [15] and hamsters [16], and gives a higher percentage of embryo development in sheep [17] and pigs $[15,18]$. Previous studies with prepubertal goat oocytes [19] have shown that $100 \mu \mathrm{M}$ of cysteamine added to the maturation medium significantly improves the percentage of oocytes with 2 pronuclei $(77.0 \%$ of total fertilised oocytes) compared to the control group (37.8\%).

The aim of this study was to assess both effects together: oocyte selection using the $\mathrm{BCB}$ test plus the addition of cysteamine to the maturation medium to improve the in vitro embryo development of prepubertal goat oocytes.

\section{MATERIALS AND METHODS}

\subsection{Oocyte collection}

The ovaries were obtained from goats, 45 to 60 days old, from a local slaughterhouse and transported at $37^{\circ} \mathrm{C}$ in Dulbecco phosphate-buffered saline (PBS, P-4417, Sigma) containing $50 \mu \mathrm{g} \cdot \mathrm{mL}^{-1}$ of gentamycin. The oocytes were recovered by slicing the ovaries in TCM199 (Sigma, B-2520), supplemented with $135 \mu \mathrm{g} \cdot \mathrm{mL}^{-1} \mathrm{NaHCO}_{3}$, $11.1 \mu \mathrm{g} \cdot \mathrm{mL}^{-1}$ heparin-sodium salt $(\mathrm{H}-3393$, 170 USP $\cdot \mathrm{mg}^{-1}$ Sigma), 2\% (v/v) steer serum (Donor Bovine Serum ${ }^{\circledR}$, CanSera, Ontario, Canada) and $50 \mu \mathrm{g} \cdot \mathrm{mL}^{-1}$ gentamycin. Oocytes with one or more complete layers of cumulus cells and homogeneous cytoplasm were selected. Selected oocytes were randomly distributed among the treatment groups.

\subsection{Brilliant cresyl blue test}

Immediately after oocyte collection, the oocytes were washed 3 times in mPBS (PBS with $1090 \mathrm{mg} \cdot \mathrm{L}^{-1}$ glucose, $35.2 \mathrm{mg} \cdot \mathrm{L}^{-1}$ pyruvate, $0.4 \%$ (w/v) BSA, Sigma, A-9647, fraction $\mathrm{V}$ ) and $50 \mu \mathrm{g} \cdot \mathrm{mL}^{-1}$ gentamycin. Then the oocytes were exposed to $26 \mu \mathrm{M}$ of BCB (Sigma, B-5388) diluted in mPBS for 90 min at $38.5^{\circ} \mathrm{C}$ in a $5 \% \mathrm{CO}_{2}$ humidified air atmosphere. Following $\mathrm{BCB}$ exposure, the oocytes were washed 3 times in $\mathrm{mPBS}$ and were classified into 2 groups, depending on their cytoplasm coloration; $\mathrm{BCB}+$ oocytes showed a blue cytoplasm coloration and BCB-oocytes no blue coloration. After classification, the oocytes were washed 3 times in a maturation medium.

\subsection{In vitro maturation of oocytes}

The maturation medium was TCM199 (Sigma, M-7528) supplemented with $275 \mu \mathrm{g} \cdot \mathrm{mL}^{-1}$ sodium pyruvate, $146 \mu \mathrm{g} \cdot \mathrm{mL}^{-1}$ L-glutamine, $10 \%(\mathrm{v} / \mathrm{v})$ steer serum, $10 \mu \mathrm{g} \cdot \mathrm{mL}^{-1}$ o-LH (Sigma, L-5269), $10 \mu \mathrm{g} \cdot \mathrm{mL}^{-1}$ o-FSH (Ovagen $^{\circledR}$, Immuno Chemicals Products 
Ltd., Auckland, New Zealand), $1 \mu \mathrm{g} \cdot \mathrm{mL}^{-1}$ $17 \beta$ estradiol (Sigma, E-2257), $100 \mu \mathrm{M}$ cysteamine (Sigma, M-9768) and $50 \mu \mathrm{g} \cdot \mathrm{mL}^{-1}$ gentamycin. Groups of 20 to 25 oocytes were transferred to $100 \mu \mathrm{L}$ microdrops of maturation medium and incubated for $27 \mathrm{~h}$ at $38.5^{\circ} \mathrm{C}$ in a humidified air atmosphere of $5 \% \mathrm{CO}_{2}$ under mineral oil (Sigma, M-3516). The control group consisted of oocytes not exposed to the BCB test and matured in the above maturation medium but without cysteamine.

\subsection{Sperm preparation}

At the end of the maturation period, the oocytes were inseminated with fresh semen. The ejaculates were collected from 2 Murciano bucks of proven fertility into artificial vaginas and were transported at $37{ }^{\circ} \mathrm{C}$ within $30 \mathrm{~min}$ to the laboratory. The motility of the sperm cells was evaluated under an inverted microscope and the motile sperm fraction was separated by swim-up. Seventy microliters of semen was placed in each of several conical tubes under a $2 \mathrm{~mL}$ Defined Medium [20] modified by Younis et al. [21] and referred to as $\mathrm{mDM}$ here, and then incubated for 45 to $60 \mathrm{~min}$ in a humidified atmosphere of $5 \% \mathrm{CO}_{2}$ in air at $38.5^{\circ} \mathrm{C}$. After incubation, $600 \mu \mathrm{L}$ from the top of each tube was removed and pooled in a sterile $15 \mathrm{~mL}$ centrifuge tube and centrifuged at $200 \times g$ for $10 \mathrm{~min}$. After dis carding the supernatant, the resulting sperm pellet was resuspended 1:1 with $\mathrm{mDM}$ medium containing heparin $\left(100 \mu \mathrm{g} \cdot \mathrm{mL}^{-1}\right.$ heparin-sodium salt; $\left.170 \mathrm{USP} \cdot \mathrm{mg}^{-1}\right)$ and was incubated for 45 to $60 \mathrm{~min}$ in a humidified air atmosphere of $5 \% \mathrm{CO}_{2}$ at $38.5^{\circ} \mathrm{C}$ (final concentration: $84 \times 10^{6} \mathrm{sperm} \cdot \mathrm{mL}^{-1}$, approximately).

\subsection{In vitro fertilisation of the oocytes}

After maturation, groups of 20 to 25 oocytes were transferred into $100 \mu \mathrm{L}$ fertilisation microdrops of modified Tyrode medium (TALP), as described by Parrish et al. [22] supplemented with $1 \mu \mathrm{g} \cdot \mathrm{mL}^{-1}$ hypotaurine (Sigma, H-1384) under mineral oil. After capacitation, the sperm concentration was assessed with a hemacytometer, and an aliquot $(5 \mu \mathrm{L})$ of the sperm suspension was added to the fertilisation microdrops (final concentration: $3.5 \times 10^{6} \mathrm{sperm} \cdot \mathrm{mL}^{-1}$ ). We cultured it for $24 \mathrm{~h}$ in a humidified air atmosphere of $5 \% \mathrm{CO}_{2}$ at $38.5^{\circ} \mathrm{C}$.

\subsection{Evaluation of oocytes after IVM and IVF}

To evaluate the nuclear stage after maturation, a sample of oocytes was fixed at $27 \mathrm{~h}$ of IVM and stained with 1\% lacmoid (Sigma, L-7512). Oocyte maturation was measured by the percentage of oocytes reaching the Metaphase II (MII) stage.

To evaluate the pronuclear stage after $20 \mathrm{~h}$ of IVF, a sample of oocytes was processed in the same way as the oocytes fixed after IVM. The oocytes with a sperm in the cytoplasm were considered fertilised and were then classified into 1 of 3 groups: $2 \mathrm{PN}$ (female pronucleus, male pronucleus and sperm tail; normal fertilisation), polyspermy ( 2 or more sperm tails in the cytoplasm with condensed heads or two or more decondensed heads in the cytoplasm), and asynchrony (female pronucleus and a condensed sperm head).

The sperm heads were classified into 4 types according to their morphological changes in the cytoplasm [23]: Condensed head (Ch); Swollen head (Sh); Metaphase chromosomes of the sperm nucleus (Mc) and Male Pronucleus (MPN).

\subsection{In vitro embryo culture}

Following $24 \mathrm{~h}$ of sperm-exposure, the oocytes in the culture medium were washed with the aid of a fine pipette to separate the oocytes from any sperm cells. The embryos were cultured in groups of 20 to 25 embryos 
in 20 to $25 \mu \mathrm{L}$ microdrops $(1 \mu \mathrm{L}$ culture medium/embryo) of Synthetic Oviductal Fluid (SOF [24]) modified by Takahashi and First [25] in $35 \mathrm{~mm}$ culture dishes under mineral oil in a humidified atmosphere of $5 \% \mathrm{CO}_{2}$, $5 \% \mathrm{O}_{2}$ and $90 \% \mathrm{~N}_{2}$. The presumptive embryos were maintained in culture for 7 days. The culture medium was not changed during this period. After $24 \mathrm{~h}$ in culture (that is, $48 \mathrm{~h}$ after insemination), $10 \%$ (v/v) steer serum was added to the microdrops $(0.1 \mu \mathrm{L}$ serum/embryo). At the end of the culture period, the total cell number of embryos was assessed with fluorescent microscopy after Hoechst staining and the percentage of cleaved embryos and the percentages of morulae and blastocysts were recorded.

\subsection{Statistical analysis}

The difference between the treatment groups was detected by Chi-square analysis or the Fischer exact test where appropriate. The overall chi-square was calculated and found to be significant before performing the Fischer exact test to detect differences between the treatment groups. The KruskalWallis test was performed with the Dunn Multiple Comparison post-test to analyse the differences among groups in the embryo cell number, using the GraphPad InStat (version 3.01 for Windows 95, GraphPad Software, San Diego, California, USA). The differences with a probability value of 0.05 or less were considered significant.

\section{RESULTS}

The percentage of oocytes stained by BCB was $28.6 \%(360 / 1257)$. Table I shows the oocyte nuclear maturation after $27 \mathrm{~h}$ of IVM. The oocytes at the MII stage were $89.5 \%$ and $72.1 \%$ in $\mathrm{BCB}+$ and $\mathrm{BCB}-$ oocytes, respectively. The total MII-oocytes matured with cysteamine $(77.8 \%, P<0.05)$ were higher than the control group (67.3\%)

Table II shows the IVF parameters. Oocytes normally fertilised (2 PN) were higher in $\mathrm{BCB}+$ than in $\mathrm{BCB}-$ and control group oocytes $(39.7,21.0$ and $22.2 \%$, respectively; $P<0.001)$. The oocytes with one condensed sperm head in their cytoplasm (asynchronous fertilisation) were higher in the control group than in the oocytes matured with cysteamine and exposed to BCB (13.9 vs. $6.5 \%$, respectively; $P<0.01)$. We did not find differences among groups in polyspermic oocytes, with a number of $2.8,2.7$ and 2.8 spermatozoa/oocyte in $\mathrm{BCB}+, \mathrm{BCB}-$ and the control group, respectively.

Tables III and IV show the morphological changes of the sperm head in the cytoplasm. In monospermic oocytes, the sperm heads that developed up to the

Table I. Effect of the BCB test and the addition of cysteamine in the IVM medium on the nuclear stage of in vitro matured oocytes (replicates $=3$ ) .

\begin{tabular}{ccccccc}
\hline Treatment & $\begin{array}{c}\text { Total } \\
\text { oocytes }\end{array}$ & $\begin{array}{c}\text { GV } \\
n(\%)\end{array}$ & $\begin{array}{c}\text { GVBD } \\
n(\%)\end{array}$ & $\begin{array}{c}\text { MI } \\
n(\%)\end{array}$ & $\begin{array}{c}\text { An-Tel } \\
n(\%)\end{array}$ & $\begin{array}{c}\text { MII } \\
n(\%)\end{array}$ \\
\hline $\begin{array}{c}\text { Cysteamine } \\
\text { BCB }+\end{array}$ & 105 & $0(0)$ & $0(0)$ & $11(10.5) \mathrm{b}$ & $0(0)$ & $94(89.5) \mathrm{a}$ \\
BCB- & 219 & $3(1.4)$ & $1(0.5)$ & $57(26.0) \mathrm{a}$ & $0(0)$ & $158(72.1) \mathrm{bc}$ \\
Total & 324 & $3(0.9)$ & $1(0.3)$ & $68(21.0) \mathrm{a}$ & $0(0)$ & $252(77.8) \mathrm{b}$ \\
\hline Control & 150 & $3(2.0)$ & $8(5.3)$ & $30(20.0) \mathrm{ab}$ & $0(0)$ & $101(67.3) \mathrm{c}$ \\
\hline
\end{tabular}

${ }^{a}$ Values in the same column with different letters $(\mathrm{a}, \mathrm{b}, \mathrm{c})$ differ significantly $(P<0.05)$. GV: Germinal vesicle; GVBD: Germinal vesicle breakdown; MI: Metaphase I; An-Tel: Anaphase-Telophase I; MII: Metaphase II. 
Table II. Effect of the BCB test and the addition of cysteamine in the IVM medium on the in vitro fertilisation of in vitro matured oocytes (replicates $=3)^{\mathrm{a}}$.

\begin{tabular}{cccccc}
\hline \multirow{2}{*}{ Treatment } & $\begin{array}{c}\text { Inseminated } \\
\text { oocytes }\end{array}$ & \multicolumn{5}{c}{ Fertilised oocytes, $n(\%)$} \\
\cline { 3 - 6 } & & Total & 2 PN & Asynchronous & Polyspermic \\
\hline Cysteamine & & & & & \\
BCB + & 116 & $66(56.9)$ & $46(39.7) \mathrm{a}$ & $2(1.7) \mathrm{c}$ & $18(15.5)$ \\
BCB- & 286 & $132(46.2)$ & $60(21.0) \mathrm{b}$ & $24(8.4) \mathrm{ab}$ & $48(16.8)$ \\
Total & 402 & $198(49.3)$ & $106(26.4) \mathrm{b}$ & $26(6.5) \mathrm{bc}$ & $66(16.4)$ \\
\hline Control & 144 & $78(54.2)$ & $32(22.2) \mathrm{b}$ & $20(13.9) \mathrm{a}$ & $26(18.1)$ \\
\hline
\end{tabular}

${ }^{a}$ Values in the same column with different letters $(\mathrm{a}, \mathrm{b}, \mathrm{c})$ differ significantly $(P<0.05)$. 2PN: two pronuclei + one sperm tail. Polyspermic: oocytes with two or more sperm tails in the cytoplasm with non-decondensed heads or two or more decondensed heads in the cytoplasm. Asynchronous: oocytes with a condensed sperm head and one feminine pronucleus.

Table III. Effect of the BCB test and the addition of cysteamine in the IVM medium on the morphological changes of sperm heads in monospermic oocytes (replicates $=6)^{\mathrm{a}}$.

\begin{tabular}{cccccc}
\hline Treatment & \multicolumn{5}{c}{ Monospermic oocytes, $n(\%)$} \\
\hline Cysteamine & Total oocytes & $\begin{array}{c}\text { Male } \\
\text { pronucleus }\end{array}$ & $\begin{array}{c}\text { Metaphase } \\
\text { chromosomes }\end{array}$ & $\begin{array}{c}\text { Swollen } \\
\text { head }\end{array}$ & $\begin{array}{c}\text { Condensed } \\
\text { head }\end{array}$ \\
\hline BCB + & 48 & $46(95.8) \mathrm{a}$ & $0(0)$ & $0(0)$ & $2(4.2) \mathrm{c}$ \\
BCB- & 84 & $60(71.4) \mathrm{bc}$ & $0(0)$ & $6(7.1)$ & $18(21.4) \mathrm{ab}$ \\
Total & 132 & $106(80.3) \mathrm{b}$ & $0(0)$ & $6(4.5)$ & $20(15.2) \mathrm{bc}$ \\
\hline Control & 52 & $32(61.5) \mathrm{c}$ & $0(0)$ & $0(0)$ & $20(38.5) \mathrm{a}$ \\
\hline
\end{tabular}

${ }^{a}$ Values in the same column with different letters (a, b, c) differ significantly $\left(\chi^{2}, P<0.05\right)$.

Table IV. Effect of the BCB test and the addition of cysteamine in the IVM medium on the morphological changes of sperm heads in polyspermic oocytes (replicates $=6)^{\mathrm{a}}$.

\begin{tabular}{cccccc}
\hline Treatment & \multicolumn{5}{c}{ Sperm heads penetrating oocytes, $n(\%)$} \\
\hline Cysteamine & $\begin{array}{c}\text { Total sperm } \\
\text { heads }\end{array}$ & $\begin{array}{c}\text { Male } \\
\text { pronucleus }\end{array}$ & $\begin{array}{c}\text { Metaphase } \\
\text { chromosomes }\end{array}$ & $\begin{array}{c}\text { Swollen } \\
\text { heads }\end{array}$ & $\begin{array}{c}\text { Condensed } \\
\text { heads }\end{array}$ \\
\hline BCB + & 50 & $38(76.0)$ & $4(8.0) \mathrm{a}$ & $2(4.0)$ & $6(12.0)$ \\
BCB- & 128 & $94(73.4)$ & $10(7.8) \mathrm{a}$ & $8(6.3)$ & $16(12.5)$ \\
Total & 178 & $132(74.2)$ & $14(7.9) \mathrm{a}$ & $10(5.6)$ & $22(12.4)$ \\
\hline Control & 74 & $58(78.4)$ & $0(0) \mathrm{b}$ & $2(2.7)$ & $14(18.9)$ \\
\hline
\end{tabular}

${ }^{a}$ Values in the same column with different letters $(\mathrm{a}, \mathrm{b})$ differ significantly $(P<0.05)$.

male pronucleus were $95.8 \%$ in $\mathrm{BCB}+$ and $71.4 \%$ in BCB- oocytes $(P<0.01)$. The addition of cysteamine to the maturation medium increased the formation of the male pronucleus $(80.3 \%)$ compared to the control group $(61.5 \%)$. In polyspermic oocytes (Tab. IV) we did not find these differences among the groups. 
Table V. Effect of the BCB test and the addition of cysteamine in the IVM medium on the embryo development of in vitro matured and fertilised prepubertal goat oocytes (replicates $=6)^{\mathrm{a}}$.

\begin{tabular}{|c|c|c|c|c|c|c|}
\hline \multirow{2}{*}{$\begin{array}{l}\text { Treatment } \\
\text { Cysteamine }\end{array}$} & \multirow{2}{*}{$\begin{array}{c}\text { Inseminated } \\
\text { oocytes }\end{array}$} & \multicolumn{5}{|c|}{ Embryo development at day 8 post-insemination } \\
\hline & & Cleaved & $\geq 8$ cell & Morulae + & & stocysts \\
\hline & & $n(\%)$ & $n(\%)^{\mathrm{b}}$ & $n(\%)^{\mathrm{b}}$ & $n(\%)^{\mathrm{b}}$ & No. of cells \\
\hline $\mathrm{BCB}+$ & 139 & $63(45.3) \mathrm{a}$ & $43(68.3) \mathrm{a}$ & $15(23.8) \mathrm{a}$ & $5(7.9)$ & $78.0 \pm 14.4 a$ \\
\hline $\mathrm{BCB}-$ & 392 & $137(34.9) \mathrm{b}$ & $29(21.2) \mathrm{c}$ & $7(5.1) b$ & $4(2.9)$ & $43.3 \pm 14.9 b$ \\
\hline Total & 531 & 200 (37.6)ab & $72(36.0) b$ & $22(11.0) b$ & $9(4.5)$ & $62.6 \pm 22.8 \mathrm{ab}$ \\
\hline Control & 111 & 47 (42.3)ab & $15(31.9) \mathrm{bc}$ & $6(12.8) \mathrm{ab}$ & $0(0)$ & \\
\hline
\end{tabular}

${ }^{\mathrm{a}}$ Values in the same column with different letters $(\mathrm{a}, \mathrm{b}, \mathrm{c})$ differ significantly $(P<0.05) .{ }^{\mathrm{b}}$ Percentages calculated from cleaved embryos.

Table V shows the percentages of cleavage and development to the blastocyst stage of the oocytes.

With cysteamine in the maturation medium, $\mathrm{BCB}+$ oocytes showed higher percentages of cleaved embryos $(45.3 \%)$, embryos with eight or more cells $(68.3 \%)$ and morula plus blastocysts $(23.8 \%)$ than the BCB-oocytes $(34.9 \%, P<0.05 ; 21.1 \%$, $P<0.0001$ and $5.1 \%, P<0.001$, respectively). Cysteamine increased the blastocyst rate from 0 to $4.5 \%$. The control group was not statistically different from the $\mathrm{BCB}+$ oocytes in the morula plus blastocyst percentage but we did not find any blastocysts in the control group. The number of cells was higher in the blastocysts from the $\mathrm{BCB}+$ than from the $\mathrm{BCB}-$ oocytes (78.0 \pm 14.4 vs. $43.3 \pm 14.9, P<0.05$, respectively).

\section{DISCUSSION}

This study shows that oocytes selected by the $\mathrm{BCB}$ test $(\mathrm{BCB}+$ oocytes) and matured with cysteamine significantly improved the number of oocytes reaching the MII stage, oocytes with 2 PN, oocytes with MPN formation and embryos developing up to 8 cells, compared to the oocytes in the control group. Comparing oocytes exposed to the $\mathrm{BCB}$ test, $\mathrm{BCB}+$ oocytes showed higher percentages of oocytes reaching MII, oocytes with 2 PN, oocytes with MPN formation, cleaved embryos, embryos developing beyond the 8-cell stage and the number of blastocysts cells than the BCBoocytes. Previous studies in our laboratory [4] have shown that prepubertal goat oocytes stained with BCB show significantly higher rates of nuclear maturation and normal fertilisation (2PN oocytes) than unstained oocytes (BCB-), although the percentage of blastocysts is still low (4\%). Pujol et al. [3] in calf oocytes have also shown increases in the percentages of the blastocyst yield of $\mathrm{BCB}+$ compared to $\mathrm{BCB}-$ oocytes (12.3 vs. $1.6 \%$ respectively).

The total number of oocytes matured with cysteamine (BCB+ plus $\mathrm{BCB}-)$ showed higher percentages of nuclear maturation and MPN formation than oocytes matured without cysteamine (control group) but differences were not found in any of the other studied parameters. We suggest that cysteamine had a positive effect on embryo yield from prepubertal goats only when the $\mathrm{BCB}+$ oocytes were used. RodríguezGonzález et al. [4] observed that $\mathrm{BCB}+$ oocytes were larger than $\mathrm{BCB}-$ oocytes. This could mean that complete oocyte intraovarian growth is needed before cysteamine 
could have a positive effect on oocyte maturation.

Several studies have shown that the addition of cysteamine to the oocyte maturation medium increases intracytoplasmic GSH levels in different species [14, 17, 18, 26-28]. GSH, the major non-protein sulphydryl compound in mammalian cells, is an endogenous and ubiquitous reducing agent that protects cells from oxidation and plays a number of important roles in cellular metabolism including protein synthesis and the reduction of disulphides [29]. In oocytes, intracytoplasmic GSH participates in the transformation of the fertilising sperm head in the male pronucleus. It is believed that at fertilisation, a high intracellular GSH content is needed for the transformation of the disulphide-stabilised sperm nucleus into the male pronucleus [30, 31]. Indeed, the decrease in intracellular GSH of mouse oocytes impairs the decondensation of the sperm nucleus [32]. In prepubertal goat oocytes, the high incidence of asynchronous fertilisation (oocytes with a feminine pronucleus and intact sperm head) could be due to the low intracytoplasmic GSH levels of these oocytes. Previous studies with prepubertal goats have shown that the asynchronous fertilised oocytes develop to haploid embryos [11]. In our study the percentage of cleaved embryos in the control group $(42.3 \%)$ was higher than the percentage of normally fertilised (2PN) oocytes $(22.2 \%)$. With $\mathrm{BCB}+$ oocytes, the difference between the percentage of cleaved embryos $(45.3 \%)$ and the percentage of $2 \mathrm{PN}$ oocytes (39.7\%) was reduced which suggests a lower number of haploid embryos obtained with $\mathrm{BCB}+$ oocytes matured with cysteamine. Several authors have found an effect of intracytoplasmic GSH levels on MPN formation [15, 16, 28, 31, 33, 34]. In our study we observed significantly higher percentages of MPN in oocytes matured with cysteamine compared to the control group (80.3 vs. $61.5 \%$, respectively).
In cattle [13, 14], buffalo [35] and sheep [17], the addition of cysteamine to the maturation media improves the in vitro blastocyst development. In pigs [15] the addition of 50 and $500 \mu \mathrm{M}$ cysteamine increases the percentage of 2 PN oocytes ( 43 and $45 \%$ respectively vs. $10 \%$ in the control group) but the concentration of $500 \mu \mathrm{M}$ also increases the percentage of blastocysts (12 vs. $1 \%$ in the control group). The explanation could be that both cysteamine concentrations affect the MPN formation but only the highest concentration further affects the mitotic development. Oocytes cannot incorporate cysteamine to synthesise GSH. Cysteamine acts by converting the cystine present in TCM199 (a cystine-rich medium) to cysteine and cysteine is incorporated by the oocyte to synthesise GSH (reviewed by Nagai [36]). Oocytes with or without a cumulus can take up cysteine. Mori et al. [37] have shown the effect of cumulus cells on intracytoplasmic GSH synthesis. Yamauchi and Nagai [18] have concluded that cysteamine increases the content of GSH and promotes MPN formation in cumulusfree porcine oocytes. Also, Grupen et al. [15] have reported a higher percentage of male pronucleus formation with a combination of TCM 199 and cysteamine. In our study, using $100 \mu \mathrm{M}$ of cysteamine in TCM 199 , the number of $\mathrm{BCB}+$ oocytes that developed up to 8-cell embryos was higher than the control group. However, the differences were not statistically significant in morula and blastocyst yield. We suggest that in this study, the concentration of cysteamine causes an increase in GSH intracytoplasmic concentration to aid the sperm head decondensation but not enough to increase the blastocyst formation. In our previous study [4] using $\mathrm{BCB}+$ selected oocytes matured in the same culture medium but without cysteamine, the percentage of oocytes reaching the morulae plus the blastocyst stage was $12 \%$ compared with the $23.8 \%$ reached in this study when adding cysteamine to the maturation medium. 
In conclusion, the $\mathrm{BCB}$ test selects the oocytes that respond best to the addition of cysteamine to the IVM media. The selection of oocytes using the BCB test and the addition of cysteamine in the protocol of in vitro embryo production of prepubertal goat oocytes has improved the nuclear maturation, normal fertilisation (2PN), MPN formation and embryo development up to the morula stage.

\section{ACKNOWLEDGEMENTS}

This study was supported by CICYT (Grants AGF99-1232 and AGL2000-0353). The author E. Rodríguez-González was supported by a fellowship from the Generalitat de Catalunya.

\section{REFERENCES}

[1] Ericsson SA, Boyce ML, Funahashi H, Day BN. Assessment of porcine oocytes using brilliant cresyl blue. Theriogenology 1993, 39: 214.

[2] Roca J, Martínez E, Vázquez JM, Lucas X. Selection of immature pig oocytes for homologous in vitro penetration assays with the Brilliant Cresyl Blue test. Reprod Fertil Devel 1998, 10: 479-485.

[3] Pujol M, López-Béjar M, Mertens MJ, Rodríguez-González E, Velilla E, Paramio MT. Selection of immature heifer oocytes using the brilliant cresyl blue test. Theriogenology 2000, 53: 466 .

[4] Rodríguez-González E, Lopez-Bejar M, Velilla E, Paramio MT. Selection of prepubertal goat oocytes using the Brilliant Cresyl Blue test. Theriogenology 2002, 57: 1397-409.

[5] Crozet N, Ahmed-Ali M, Dubos MP. Developmental competence of goat oocytes from follicles of different size categories following maturation, fertilization and culture in vitro. $\mathrm{J}$ Reprod Fertil 1995, 103: 293-298.

[6] Cognié Y, Poulin N, Pignon P, Sulon J, Beckers $\mathrm{J}$, Guerin Y. Does heparin affect development ability of IVF goat oocytes? Proceed $11^{\mathrm{e}}$ Reunion AETE. 1995, p 146.

[7] Pawshe C, Palanisamy A, Taneja M, Jain S, Totey S. Comparison of various maturation treatments on in vitro maturation of goat oocytes and their early embryonic development and cell numbers. Theriogenology 1996, 46: 971-982.

[8] Kenkistepe L, Luvoni C, Rzucidlo S, Brackett BG. Procedural improvements for in vitro production of viable uterine stage caprine embryos. Small Ruminant Res 1996, 20: 247-254.

[9] Kenkistepe L, Simplicio A, Brackett BG. Caprine blstocyst development after in vitro fertilization with spermatozoa frozen in different extenders. Theriogenology 1998, 49: 1265-1274.

[10] Mogas T, Palomo MJ, Izquierdo D, Paramio MT. Morphological events during in vitro fertilization of prepubertal goat oocytes matured in vitro. Theriogenology 1997, 48: 815-829.

[11] Villamediana P, Vidal F, Paramio MT. Cytogenetic analysis of caprine 2-to-4-cell embryos produced in vitro. Zygote 2001, 9: 193-199.

[12] Perreault S, Barbee R, Slott V. Importance of gluthatione in the acquisition and maintenance of sperm nuclear descondensing activity in maturing hamster oocytes. Dev Biol 1988, 125: 181-186.

[13] De Matos DG, Furnus CC, Moses DF, Baldassarre H. Effect of cysteamine on glutathione level and developmental capacity of bovine oocyte matured in vitro. Mol Reprod Dev 1995, 42: 432-436.

[14] De Matos DG, Furnus CC, Moses DF, Martínez AG, Matkovic M. Stimulation of glutathione synthesis of in vitro matured bovine oocytes and its effect on embryo development and freezability. Mol Reprod Dev 1996, 45: 451-457.

[15] Grupen CG, Nagashima H, Nottle MB. Cysteamine enhances in vitro development of porcine oocytes matured and fertilized in vitro. Biol Reprod 1995, 53 :173-178.

[16] Kito S, Bavister BD. Male pronuclear formation and early embryonic development of hamster oocytes matured in vitro with gonadotrophins, amino acids and cysteamine. J Reprod Fertil 1997, 110: 35-46.

[17] De Matos DG, Gasparrini B, Pasqualini SR, Thompson JG. Effect of glutathione synthesis stimulation during in vitro maturation of ovine oocytes on embryo development and intracellular peroxide content. Theriogenology 2002, 57: 1443-1451.

[18] Yamauchi N, Nagai T. Male pronuclear formation in denuded porcine oocytes after in vitro maturation in the presence of cysteamine. Biol Reprod 1999, 61: 828-833.

[19] Rodríguez-González E, López-Bejar M, Velilla E, Mertens MJ, Paramio MT. Male pronuclear formation in prepubertal goat oocytes after in vitro maturation in the presence of thiol compounds. Theriogenology 2001, 55: 493.

[20] Brackett BG, Oliphant G. Capacitation of rabbit spermatozoa in vitro. Biol Reprod 1975, 12: 260-274. 
[21] Younis AI, Zuelke KA, Harper KM, Oliveira MAL, Brackett BG. In vitro fertilization of goat oocytes. Biol Reprod 1991, 44: 1177-1182.

[22] Parrish JJ, Susko-Parrish JL, Leibfried-Rutledge ML, Crister ES, Eyeston WH, First NL. Bovine in vitro fertilization with frozen thawed semen. Theriogenology 1986, 25: 591-600.

[23] Kikuchi K, Nagai T, Ding J, Yamauchi N, Noguchi J, Izaike Y. Cytoplasmic maturation for activation of pig follicular oocytes cultured and arrested at metaphase II. J Reprod Fertil 1999, 116: $143-156$.

[24] Tervit HR, Whittingham DG, Rowson LEA. Successful culture of in vitro sheep and cattle ova. J Reprod Fertil 1972, 30: 493-497.

[25] Takahashi Y, First NL. In vitro development of bovine one-cell embryos: influence of glucose, lactate, pyruvate, amino acids and vitamins. Theriogenology 1992, 37: 963-978.

[26] De Matos DG, Furnus CC, Moses D. Gluthatione syntesis during in vitro maturation of bovine oocytes: role of cumulus cells. Biol Reprod 1997, 57: 1420-1425.

[27] De Matos DG, Furnus CC. The importance of having high glutathione (GSH) level after bovine in vitro maturation on embryo development effect of beta-mercaptoethanol, cysteine and cystine. Theriogenology 2000, 53: 761-771.

[28] Nagai T, Geshi M, Yonai M, Yamauchi N. Effects of cysteamine and cumulus cells on maturation and male pronucleus formation in porcine oocytes. Theriogenology 1996, 47: 196.

[29] Lafleur MVM, Hoorweg JJ, Joenge H, Westmijze EJ, Retel J. The ambivalent role of gluthatione in the protection of DNA against singlet oxigen. Free Rad Res 1994, 21: 9-17.
[30] Yoshida M, Ishigaki K, Pursel VG. Effect of maturation media on male pronucleus formation in pig oocytes matured in vitro. Mol Reprod Dev 1992, 31: 68-71.

[31] Yoshida M, Ishigaki K, Nagai T, Chikyu M, Pursel VG. Gluthatione concentration during maturation and after fertilization in pig oocytes: relevance to the ability of oocytes to form male pronucleus. Biol Reprod 1993, 49: 89-94.

[32] Gardiner CS, Reed DJ. Status of gluthatione during oxidant-induced oxidative stress in the preimplantation mouse embryo. Biol Reprod 1994, 51: 1307-1314.

[33] Funahashi H, Cantley T, Stumpf T, Terlow S, Day B. Use of low salt culture medium for in vitro maturation of porcine oocytes is associated with elevated oocyte gluthatione levels and enhanced male pronuclear formation after in vitro fertilization. Biol Reprod 1994, 51: 633-639.

[34] Perreault S, Wolff R, Zirkin B. The role of disulfide bond reduction during mammal sperm nuclear decondensation. Dev Biol 1994, 101: 160-167.

[35] Gasparrini B, Negia D, Di Palo R, Campanile G, Zicarelli L. Effect of cysteamine during IVM on buffalo embryo development. Theriogenology 2000, 54: 1537-1542.

[36] Nagai T. The improvement of in vitro maturation systems for bovine and porcine oocytes. Theriogenology 2001, 55: 1291-1301.

[37] Mori T, Amano T, Shimizu H. Role of gap junctional communication of cumulus cells in cytoplasmic maturation of porcine oocytes cultured in vitro. Biol Reprod 2000, 62: 913-919. 
